\title{
Guidelines for carrying out leprosy elimination campaigns 1996
}

\begin{abstract}
Summary A Leprosy Elimination Campaign (LEC) is an initiative which aims to detect leprosy cases, particularly the more serious ones referred to as "cases of consequence', that remain undetected in the community, and to treat them with MDT. This will subsequently reduce the delay in managing such cases in the community and ensure that the existing health services are able to treat them. It is a time-bound, onetime activity. Leprosy of consequence is defined as cases with more than five skin lesions and skin smear positive cases. Such cases are regarded as being of consequence because they act as a major source of infection in the community and are either already disabled or at high risk of becoming disabled.

LEC is a focused combination of activities which includes: orientation courses for local health workers and volunteers; community awareness creation activities; casefinding and treating every detected case immediately with MDT. These campaigns are to be carried out primarily in endemic regions where the prevalence and new case detections are high and where the gap between estimated and registered cases is large. It is a national activity, implemented by the national staff with technical cooperation from WHO and other agencies.
\end{abstract}

\section{Introduction}

Since the World Health Assembly in May 1991 adopted a resolution calling for the elimination of leprosy as a public health problem, the global prevalence of leprosy has been reduced tremendously and about 8 million cases had been cured with MDT by the end of 1996. As a result of the implementation of the global strategy and plan of action for the elimination of leprosy, the majority of endemic countries were able to significantly increase the coverage of leprosy services, resulting in an increased detection of previously undiagnosed cases. However, the availability of health services and their capacity to implement MDT services for leprosy vary widely from country to country.

The focus of the elimination strategy is to reduce the burden of the disease as quickly as possible, thereby reducing the prevalence to below 1 case per 10,000. In theory, if all cases were to be detected within the first year of onset of disease and were treated with MDT, the impact on transmission should be visible within a few years. In practice, the detection of leprosy globally has remained unchanged over the last ten years both in terms of absolute numbers and number of smear-positive cases. This is mainly attributable to the slow progression of MDT implementation and the presence of a large number of undetected (hidden) cases.

Reproduced by kind permission of WHO, Action Programme for the Elimination of Leprosy, 20 Avenue Appia, $\mathrm{CH}-1211$ Geneva 27, Switzerland. An updated set of Guidelines is currently in preparation. 
These hidden cases are individuals who have not been diagnosed and treated by the health services even though they have had signs and symptoms of leprosy for some time. This could be because they do not know they have leprosy, or they suspect or know they have leprosy but, because of the stigma, do not want to be identified for treatment or, in some instances, do not know where to go for treatment. In some area, depending on the effectiveness of the elimination programme, this pool of hidden cases could be quite large. Thus, among the new cases reported yearly by the national programmes, only a small proportion of them are true incident cases. It is estimated that between 1996 and the year 2000, around 2 million additional cases are to be detected and treated in order to achieve the goal of elimination.

The WHO's Global Plan of Action for Elimination of Leprosy includes specific and flexible approaches to address these issues by strengthening technical support at the country level, leprosy elimination campaigns (LEC) and special action projects (SAPEL), organizing supplies of MDT drugs, leprosy elimination monitoring (LEM), simplified disability prevention and management, and the promotion and development of community action. LEC is an initiative which is a time-bound, one-time action, aimed at detecting and treating hidden cases, primarily in a specific high endemic area. It is an effort to provide additional external in-puts to improve control activities, with the involvement of local health staff and community members. It is a national activity, implemented by the national staff with technical cooperation from WHO and other agencies.

\section{Objectives of the leprosy elimination campaign}

The main objective of an elimination campaign is to detect and treat hidden leprosy cases, particularly cases of consequence, in a given area. This will subsequently reduce the delay in managing such cases in the community and will ensure that the existing health services are able to treat them.

Leprosy of consequence is defined as cases with more than five skin lesions and skin smear positive cases (where facilities for skin smears are available and reliable).

\section{Elements of LEC}

LEC is meant to complement routine leprosy elimination measures carried out at the community level. The LEC strategy is based on a combination of three elements, namely, capacity building measures for local health workers to improve MDT services; increasing community participation to strengthen elimination activities at the peripheral levels; and diagnosing and curing patients. The approach taken may vary from country to country, or even between regions within each country, depending on local situations and resources.

The activities carried out under LEC should ultimately lead to detecting and treating leprosy cases. The proposed activities to be carried out are:

- orientation workshops for local health workers and community volunteers;

- community awareness creation activities using various forms of mass media and information sessions;

- case-finding through passive methods; and

- treating every detected case immediately with MDT. 


\subsection{ORIENTATION WORKSHOPS FOR LOCAL HEALTH WORKERS AND COMMUNITY VOLUNTEERS}

The aim is to enable every peripheral health centre to provide MDT services to leprosy patients living within their jurisdiction. This will improve the accessibility of patients to treatment. In addition, communities — by informing their leaders and health volunteers about leprosy-will improve awareness of the disease and promote greater community participation in the leprosy elimination process.

\subsection{COMMUNITY AWARENESS CREATION}

Before and during the time of the campaign, various forms of mass media are to be used to supplement the information meetings held at the village/community level by creating greater awareness about leprosy, especially in areas where a campaign is centred. This could be in the form of radio messages, TV spots, newspaper articles and flyers (pamphlets).

\subsection{CASE-FINDING}

Case-finding is to be done by increasing community awareness and by visits of campaign teams to each village/community to provide services for diagnosis and treatment in addition to the services present in that area.

The main aim is to diagnose leprosy of consequence. Skin smear positive cases and cases with more than five lesions are regarded to be of consequence because they are acting as a source of infection in the community and are likely to be suffering from disability/impairment or have a high potential to become disabled in the future. This does not in any way exclude diagnosing leprosy with fewer than five skin lesions, or paucibacillary cases. Treatment will be provided to every individual diagnosed as a case of leprosy. As the campaign is not to be organized as an active case-finding project in which the total population is screened, it is more likely that only individuals with obvious skin lesions will come forward and that the campaign will mostly be picking up only leprosy of consequence.

Some cases presenting themselves during the visit of the campaign team as new cases could either be defaulters or cases that were discharged after completing treatment. Such cases will be screened by eliciting their past treatment history and, if possible, by looking at past treatment records (should they be available) with the local health worker. Former leprosy patients who have completed treatment should not be re-registered for treatment.

Household contacts of new cases will be examined if possible by the campaign team at the time the patient is diagnosed. If it is not possible to screen all contacts, the patient should be advised to bring contacts along for examination to the nearest local health centre sometime during their subsequent visits.

\subsection{TREATMENT WITH MDT}

Patients diagnosed by the campaign teams are to be treated with WHO-MDT fixed-duration treatment regimen using blister packs. Should a patient be unable to collect the MDT drugs on a monthly basis, a flexible treatment schedule is to be used for the monthly dose of MDT by entrusting either family members or volunteers to supervise the treatment. 
All new cases and defaulters (who need treatment) identified by the special teams will be provided with the first dose of appropriate MDT by the team, and case records should be handed over immediately to the local health worker who will be responsible in the village/ community for ensuring further treatment.

Although the campaign will not directly address such issues as disability prevention and other skin diseases at individual patient level, these problems are to be handled by providing health education, by utilizing services currently provided by the local health worker or by referring cases to the nearest health centre.

\section{Planning for leprosy elimination campaign}

Activities spelt out in the LEC are to be implemented by national staff with technical cooperation from WHO and other agencies.

\subsection{SELECTION OF AN AREA FOR A LEPROSY ELIMINATION CAMPAIGN (ANNEX 1)}

The campaign approach will only be relevant in some countries, or in certain areas of large countries. The following criteria will be given priority consideration in identifying an area suitable for campaign activities. However, some adjustment may be made to accommodate local situations.

a) High prevalence and detection (absolute numbers and rates).

b) Large gap between estimated and registered cases.

c) High grade 2 disability proportion among new cases.

d) An area with around 500,000 population. For areas with a high population density the whole administrative area could be taken.

e) It should be an area where villages/communities are easily accessible.

f) MDT services are presently available in the area and there is a health infrastructure to ensure continuity of treatment (cases detected by the campaign must be able to complete the required course of chemotherapy).

g) There is community acceptance for LEC activities.

\subsection{PROPOSAL DEVELOPMENT}

A detailed proposal for conducting LEC will be developed by the national programme in consultation with the local health authorities and organizations who are going to be involved in the various campaign activities. If needed, on-site visits to the selected region by those who are developing the proposal should be encouraged so that a realistic proposal can be developed which takes into consideration the present local situation (manpower, transport and other logistics). This proposal is to be submitted to WHO by the national programme manager.

\subsection{TIME FRAME AND TIMING OF LEC}

The campaign is to last for a limited period (three to four months) and, because of its time-bound nature, it should be regarded as a special effort to boost elimination measures at the peripheral level. Since LEC is an intensive activity involving all health care facilities and 
personnel in the area, conducting it for a longer period is likely to disturb the routine activities in the area and risk a loss of momentum.

The timing of the campaign should also be taken into consideration while developing the proposal. LEC should be conducted during the months or season when it is most likely that the majority of the community members will be in the village/community at the time of the campaign team's visits.

Certain activities initiated by the campaign are expected to be sustained by the local health workers and volunteers after the end of LEC. Normally some elements of LEC will become part of routine activities. However, if necessary another LEC may be implemented in the same area after $1-2$ years.

\subsection{PHASES OF LEC}

LEC will have two phases. In the first phase, campaign teams are to visit health centres and conduct short orientation workshops for local health workers (Annex 2) and volunteers (Annex 3). These workshops will provide an opportunity to reinforce the National Leprosy Control Programme's commitment towards elimination efforts. They will also highlight leprosy as a priority disease to be addressed by the local health personnel, especially at the community level. In addition, the campaign teams will be providing on the job training (diagnosis, classification, treatment, management of reactions) to local health workers. Volunteers from nearby villages/communities will be mobilized to support leprosy control activities. The main aim of involving volunteers is to make them alert to possible cases in their community, to refer suspected cases to the nearest health centre and to help patients to obtain treatment regularly.

In the second phase, campaign teams will visit villages/communities on fixed dates to conduct information meetings for the general public and community leaders (including religious leaders) as well as to diagnose and treat new cases. Information meetings are to be held to inform the public about MDT and the signs of leprosy with the use of posters and pictures. A public address system may be used, where available, to send out messages about MDT, signs of leprosy, and opportunities for diagnosis and treatment, and to encourage individuals with suspicious lesions to come forward for examination.

\subsection{ORGANIZATION OF A CAMPAIGN TEAM}

The National Programme Manager (NPM) has overall responsibility for LEC. However, the programme manager is not expected to be actually involved in the day to day implementation of the campaign. A project manager (PM) is to be selected from among the mid-level managers with experience in public health management. This person is to be made responsible for the day to day running of the campaign as well as being financially accountable. This person should whenever possible be selected from the area where LEC is to be conducted.

Under the PM, campaign teams are to be formed headed by a health worker (Team Leader) experienced in leprosy control measures, and capable of conducting workshops for local health workers and volunteers. The Team Leaders (TL) will work for the LEC on a fulltime basis for the period of the campaign (Annex 4). Each TL will be assisted by a field worker to support him/her in his/her travels from village to village and also in preparing and carrying out health information sessions. The local health worker responsible for the 
villages/communities where the campaign team is going to operate should be included as the third member of the team for the period the campaign is being conducted in his/her jurisdiction. This health worker will join the special team for the days the team is operating in his/her area, and will receive allowances similar to other members of the team. In addition, one or more volunteers will be helping the campaign team during visits to villages/ communities.

The number of teams to be formed will depend on the availability of health workers, the geography of the area, and the population and number of villages/communities to be covered. An average of 10 campaign teams are to be formed for each campaign and these teams will be mobile, moving from village to village and from one health centre to another.

\subsection{RECRUITMENT OF VOLUNTEERS}

Volunteers are to be selected by the community, taking into consideration the need to identify people motivated to do something for leprosy patients in their own community. Local community leaders could help in identifying such volunteers. A minimum of one volunteer per village/community should be recruited. In communities where it is difficult for male volunteers to treat females or vice-versa, both male and female volunteers may need to be recruited. Should there be voluntary health workers already identified and trained present in the community, these volunteers should be used in the campaign.

\subsection{INTERNAL IN-PUTS}

The major in-puts needed from the national programme are:

- identification of problem areas which could benefit by conducting LEC;

- information regarding the geography of the area, maps showing the location of health centres in relation to villages/communities;

- identification and assignment of a project manager;

- recruitment of TLs who will be heading campaign teams, to be undertaken by the programme manager in collaboration with the project manager;

- supply campaign teams with a public address system for holding health information sessions;

- selection of appropriate information materials for the mass media and/or production of posters and pamphlets in the local language;

- translation and production of guidelines for workshops for volunteers and local health workers; and

- arranging transport for use by campaign staff.

Since one of the criteria for selecting an area for LEC is good communications, new vehicles will not be provided and the campaign teams should be able to use existing local or public transport. The project manager will also use existing transport that is at his/her disposal for supervision and monitoring purposes. The actual cost for travel will be provided for campaign team members.

\subsection{EXTERNAL IN-PUTS}

The following external in-puts will be needed:

- external resources for travel and per diem of PM and campaign team members;

- funds for short workshops for local health workers; 
- funds for orientation workshops for volunteers;

- template for LEC posters promoting MDT and early diagnosis of leprosy (to be adapted for local use);

- funds for producing LEC posters in local language;

- funds for producing guidelines for eliminating leprosy in local language;

- workshop guidelines for health workers and volunteers; and

- MDT drugs in blister packs.

\subsection{DRUGS}

The required number of MDT blister packs should be made available to the project manager of LEC by the National Leprosy Control Programme from existing stock. Should a large number of cases be detected by the campaign, additional drug needs must be taken into consideration when the next shipment of drugs is made by the medical stores department, or by $\mathrm{WHO}$ at the request of the national programme.

\section{Supervision and monitoring}

\subsection{SUPERVISION AND MONITORING AT CAMPAIGN AREA LEVEL}

Supervision and monitoring of the campaign is to be undertaken by the project manager. On-site visits and progress reports (Annex 5) from each team will be used to monitor the campaign. Scheduled activities, cost, cooperation of various parties, participation of community and personnel (staff carrying out their assigned duties) are factors to be monitored.

\subsection{SUPERVISION AND MONITORING AT THE NATIONAL LEVEL}

Supervision and monitoring of each campaign is to be carried out by analysing the progress reports and final report submitted by the project manager, in addition to making site visits to some of the villages/communities where LEC has been conducted, in order to validate the progress reports submitted by the teams. The supervision and monitoring at this level is to be undertaken by the National Programme Manager and consultants, or by someone delegated to do this task by the National Programme. Indicators to be used are:

- number of new cases detected during the campaign period (PB and MB);

- proportion of new cases with more than five skin patches;

- proportion of new cases with grade 2 disability;

- proportion of villages in the area covered by the campaign teams;

- population covered by the campaign;

- number of volunteers involved in the LEC activities; and

- number of health workers involved in the LEC activities.

\subsection{EXTERNAL EVALUATION OF LEC}

An over-all evaluation of the campaign (post-LEC evaluation) is to be conducted jointly by the national programme and WHO after one to three years to determine the impact of the LEC and to assess the cure rates of cases detected by the campaign teams. 


\section{Main activities for conducting LEC}

The following are the main activities to be carried out for LEC.

6.1. PREPARATION STAGE (TWO TO THREE MONTHS)

a) Selection of an area for LEC.

b) Developing a proposal.

c) Submitting a proposal for LEC to WHO (Annex 6).

d) Approval of proposal by WHO.

e) Assignment of a project manager.

f) Advocacy meeting with local administrative officials, health authorities, health workers who will be involved in campaigns and village/community leaders, explaining the objectives and broad activities of the campaign.

g) Recruitment of staff for campaign teams or re-allocation and deployment of existing staff.

h) Recruitment of volunteers from villages/communities in the project area.

i) Production in local language of posters, pamphlets and guidelines.

j) Obtain MDT blister packs for use by campaign teams.

k) Make arrangements for a public address system for use in the information sessions.

1) Coordinate with local radio station, TV station and newspapers to obtain their support in creating awareness about leprosy, especially during the time of the campaign.

m) Mobilization of transport or arranging transport for campaign teams.

n) Start public awareness creation through the mass media at the national level, or, most importantly, in the campaign area.

\subsection{IMPLEMENTATION STAGE (TWO TO THREE MONTHS)}

a) Formation of campaign teams.

b) Briefing of TLs for LEC (Annex 4).

c) Briefing members of the LEC project, local health authorities and health workers to explain in detail the activities to be carried out.

d) Send information to various health centres regarding the visit of campaign teams to conduct workshops and the category of health workers required to attend the courses.

e) Send information to volunteers about where and when to report for training.

f) Campaign teams travel to health centres and conduct workshops for local health workers and volunteers.

g) Each team draws up a tour programme in consultation with local health staff and volunteers.

h) Campaign teams travel to villages/communities and arrange information sessions, casefinding (passive), treatment and on the job training for local health workers.

i) Each campaign team fills in a report (annex 5) for each village/community.

j) Supervision and monitoring of activities by the National Programme Manager and Project Manager.

k) Continue to create awareness about leprosy especially in the campaign areas through use of mass media (TV, and national or local radio and newspapers).

1) Preparation and submission of final report by the project manager. 
6.3. FINAL REPORT SUBMISSION STAGE (IMMEDIATELY AFTER THE END OF LEC)

A final report (Annex 7) is to be submitted to WHO by the National Programme Manager, covering general information and the leprosy situation of the area, activities carried out, achievements, financial statement and overall comments.

\section{Possible problems that could arise in conducting LEC}

a) Conflicts between the local health workers and volunteers could arise when the campaign team leaves the area if proper links and each person's roles are not properly understood.

b) The general services might regard LEC as an outside activity and not take responsibility for the cases identified by the teams if they are not fully involved in all stages of the campaign.

c) The general health sector may not be able to provide services as expected by the patients and this could result in poor treatment compliance.

d) Failure to inform and involve local community leaders regarding the objectives and timing of the campaign could result in lack of participation on their part.

e) Volunteers from villages/communities may be difficult to recruit or they might not be well motivated for the task.

f) The campaign team could focus only on detection of early cases which could result in not meeting the objectives of the campaign.

g) Volunteers, if they are not properly briefed, may be over enthusiastic in suspecting cases, which could cause some problems with the community members.

h) The campaign teams may not be able to follow the time schedule which could mean having to extend the campaign period, resulting in an increase in cost. 
Annex 1.

\section{Criteria for selecting an area for leprosy elimination campaign (LEC)}

Name of area (state/province/district)

1. Registered prevalence (numbers)

2. Population density

3. New cases detected (numbers)

4. New case MB proportion

5. Estimated and Registered leprosy case ratio

6. Proportion of disabled (WHO grade 2) among newly detected patients

7. Accessibility (communications)

8. Health inf rastructure coverage of population

9. Staff availability for LEC

10. Technical manual available in local language

11. Availability of a competent Project Manager to manage LEC

TOTAL SCORE

\section{Definition and scoring of each criterion}

1. REGISTERED PREVALENCE

Number of patients registered for chemotherapy in the region selected for LEC (using the most recent data available).

The regions tentatively selected for LEC are to be ranked according to the total registered prevalence. The top five regions are to be grouped in the category of high and given a score of 10. The lowest five regions are to be grouped under low and given a score of 1 , while the remaining regions between these two groups are to be taken as belonging to the moderate group and given a score of 5 .

\section{POPULATION DENSITY}

Number of population per square mile or square kilometer in the region selected for LEC. The regions tentatively selected for LEC are to be ranked according to the population density. The top five regions are to be grouped in the category of high and given a score of 5 . The lowest five regions are to be grouped under low and given a score of 1 and the remaining regions between these two groups are to be taken as belonging to the moderate group and given a score of 3 .

\section{NEW CASES DETECTED}

Number of new cases detected in the region selected for LEC during the year (using the most recent data available).

The regions tentatively selected for LEC are to be ranked according to the total number of new cases detected. The top five regions are to be grouped in the category of high and given a 
score of 10. The lowest five regions are to be grouped under low and given a score of 1 , and the remaining regions between these two groups are to be taken as belonging to the moderate group and given a score of 5 .

\section{NEW CASE MB PROPORTION}

Proportion of MB cases among newly detected cases in the region selected for LEC during the year (using the most recent data available).

The regions tentatively selected for LEC are to be ranked according to the new case MB proportion. The top five regions are to be grouped in the category of high and given a score of 5. The lowest five regions are to be grouped under low and given a score of 1 , and the remaining regions between these two groups are to be taken as belonging to the moderate group and given a score of 3 .

\section{ESTIMATED AND REGISTERED LEPROSY CASE RATIO}

This is the ratio between the estimated total number of leprosy cases in the region selected for LEC and the registered prevalence in that same region.

Regions with a ratio of three and above are to be grouped as high and given a score of 10 , a ratio of two (moderate) is to be given a score of 5 and a ratio of one (low) is to be given a score of 1 .

\section{PROPORTION OF DISABLED (WHO GRADE 2) AMONG NEWLY DETECTED PATIENTS}

Proportion of new cases with disability grade 2 among all new cases of whom the disability grading is known in the region selected for LEC during the year.

The regions tentatively selected for LEC are to be ranked according to the proportion of disability among newly detected cases. The top five regions are to be grouped in the category of high and given a score of 5. The lowest five regions are to be grouped under low and given a score of 1 , and the remaining regions between these two groups are to be taken as belonging to the moderate group and given a score of 3 .

\section{ACCESSIBILITY (COMMUNICATIONS)}

Communications between villages/communities in the region selected for LEC. The number of villages/communities per square mile or square kilometer is to be used as a rough measure for accessibility.

The regions tentatively selected for LEC are to be ranked according to the villages/ communities per square mile or square kilometer. The top five regions are to be grouped in the category of high and given a score of 5. The lowest five regions are to be grouped under low and given a score of 1 , and the remaining regions between these two groups are to be taken as belonging to the moderate group and given a score of 3 .

\section{HEALTH INFRASTRUCTURE COVERAGE OF POPULATION}

This is the population covered by the existing health infrastructure. It is calculated by dividing the population in the region by the number of health outlets available (including mobile centres) in the region selected for LEC. 
The regions tentatively selected for LEC are to be ranked according to the health inf rastructure coverage of population, starting with regions having the best coverage. The top five regions having the best coverage are to be grouped in the category of high and given a score of 5. The lowest five regions are to be grouped under low and given a score of 1 , and the remaining regions between these two groups are to be taken as belonging to the moderate group and given a score of 3 .

9. STAFF AVAILABILITY FOR LEC

This refers to the availability of experienced health workers to head the LEC teams which will be conducting training courses at health workers and information meetings in villages/ communities.

If the staff are readily available in the region selected for LEC, it should be grouped as high and given a score of 5. Should staff required for LEC be mobilized from neighbouring areas, it is to be grouped as moderate and given a score of 3 . If there are no staff available, then it should be grouped as low and given a score of 1 .

10. TECHNiCAL MANUAL AVAILABLE IN LOCAL LANGUAGE

This refers to the availability of a technical manual on leprosy in the local language. If there is a manual available, a score of 5 is given and if there is nothing, a score of 1 is given.

11. AVAILABILITY OF A COMPETENT PROJECT MANAGER

A person with a public health management background who will be designated as the Project Manager should be identified from the area where LEC is to be conducted.

If this person can be identified from the LEC area, a score of 5 is given. If no one can be identified and someone from outside the area must be recruited, a score of 1 is to be given. 
Annex 2.

\section{Workshop on leprosy elimination campaigns for local health workers}

Location: $\quad$ Health centre (rural or urban).

Trainers: $\quad$ Team Leader and the head of the rural/urban health centre.

Number of trainees: 10 to 20 local health workers.

Duration: Will depend on the training already received and the current level of involvement in the National Leprosy Elimination Programme.

Number of courses: As required.

Topics: $\quad$ Please refer to 'Guidelines for Workshop on Leprosy Elimination Campaign for Local Health worker'. 
Annex 3.

\section{Orientation workshop on leprosy for volunteers}

Location:

Health centre (rural) or nearby large village which is centrally located.

Trainers:

Team Leader and head of the local health centre.

Number of trainees: About 40 persons.

Duration:

4 hours (one morning or evening).

Number of courses: As required (estimated to be around 25 to 50 for an area with a population of 500,000$)$.

Topics:

Please refer to 'Guidelines for Orientation Workshop on Leprosy Elimination Campaign for Volunteers'

Role of volunteers in leprosy elimination:

a) To suspect leprosy cases from skin lesions and refer them to a health facility for diagnosis.

b) To help in promoting community awareness about the signs and symptoms of leprosy, and encouraging self-reporting to health facilities.

c) To assist the health worker in the delivery of MDT to patients who are unable to attend clinics for reasons such as old age, severe disability and living in remote places.

d) Reminding patients about clinic days and helping defaulters to return for treatment. 
Annex 4.

\section{Guidelines for briefing of team leaders for leprosy elimination campaigns}

\section{Background of team leaders}

These are senior workers experienced in leprosy who will be recruited either from within the area where the campaigns are to be conducted or from outside. They may be recruited from within the staff employed by the national programme or by NGOs.

\section{Activities}

1. Draw a detailed plan to conduct LEC.

2. Conduct a Workshop on LEC at the respective health centre for the local health workers on leprosy elimination activities.

3. Conduct a Orientation Workshop at the respective health centre or at a suitable place for volunteers on leprosy.

4. Hold information sessions about leprosy at the village/community levels for community leaders and members.

5. Screening of suspected leprosy cases, diagnosing and treating new cases with MDT (fixed duration treatment).

6. Filling in of reports and submitting reports regularly.

\section{Prerequisite for training}

Thorough knowledge of 'A Guide to Eliminating Leprosy, WHO 1995' and 'Training Manual for Volunteers'.

\section{Operational plan for each special team}

In a region selected for LEC, an average of 10 campaign teams are expected to be formed. Each team will be headed by a team leader (TL). The TLs are to be given a one day briefing so that they understand the objectives and activities to be carried out under LEC and know the Guide to Eliminating Leprosy. The trainers will be the National Programme Manager, the Project Manager and other experts.

After receiving the above mentioned briefing, the TLs will travel to the respective LEC region or to their assigned areas, depending on where the briefing is given. They will then conduct a Workshop on LEC for local health workers. These workshops are to be carried out at the health centre level. Local health workers who are currently involved in leprosy elimination activities are to attend this workshop.

Orientation Workshops for volunteers are also to be conducted at the health centre or at a place to which it will be convenient for the majority of the volunteers to travel. 
After completing the workshops, the special team will travel to each village/community to conduct information sessions.

Each team will be composed of two fixed members and one rotating member. The fixed team members are the team leader and a health worker. This health worker will help the team leader in setting up information meetings and in travelling from one village/community to another. The rotating member will be the local health worker who is in charge of leprosy activities for the village/community which the campaign team is visiting to carry out information sessions. When the campaign team has finished work in this area, it will move to the next area and will be joined by another local health worker who is responsible for that area.

Team Leader: Selection, training and job description

\begin{tabular}{|c|c|c|c|c|}
\hline ACTIVITY & WHO WILL DO? & WHERE? & HOW? & TIME \\
\hline 1. Selection of TLs & NPM and PM & $\begin{array}{l}\text { Central or } \\
\text { Regional level }\end{array}$ & Usual local channels & $\begin{array}{l}\text { During the pre- } \\
\text { paratory phase }\end{array}$ \\
\hline 2. Briefing of TLs & $\begin{array}{l}\text { NPM, PM and } \\
\text { experts }\end{array}$ & $\begin{array}{l}\text { Central or } \\
\text { Regional level }\end{array}$ & $\begin{array}{l}\text { Using varous WHO } \\
\text { guidelines* }\end{array}$ & $1-2$ days \\
\hline 3. Travel to LEC area & TLs & $\begin{array}{l}\text { From centre to } \\
\text { the capital of } \\
\text { LEC area }\end{array}$ & Local transport & 1 day \\
\hline $\begin{array}{l}\text { 4. Briefing at LEC area, } \\
\text { meeting with local health } \\
\text { authorities, community } \\
\text { leaders, listing villages, } \\
\text { health workers, volunteers, } \\
\text { preparing timetable, assign } \\
\text { sub-areas to each TL }\end{array}$ & $\begin{array}{l}\text { PM and local } \\
\text { health of ficials }\end{array}$ & At LEC capital & $\begin{array}{l}\text { Meeting, review of } \\
\text { registers, maps, travel } \\
\text { arrangements, list of } \\
\text { contact persons in } \\
\text { different sub-areas }\end{array}$ & 1 day \\
\hline $\begin{array}{l}\text { 5. Travel to health centre or } \\
\text { sub-area capital }\end{array}$ & TL & - & Local transport & 1 day \\
\hline $\begin{array}{l}\text { 6. Briefing at health centre } \\
\text { or sub-area capital }\end{array}$ & $\begin{array}{l}\text { Local health } \\
\text { personnel and TL }\end{array}$ & $\begin{array}{l}\text { At health centre } \\
\text { or sub-area } \\
\text { capital town }\end{array}$ & $\begin{array}{l}\text { Discussion with local } \\
\text { health of ficials and } \\
\text { community leaders }\end{array}$ & Half a day \\
\hline $\begin{array}{l}\text { 7. Conduct workshop for } \\
\text { local health workers }\end{array}$ & $\begin{array}{l}\text { TL and local } \\
\text { health officials }\end{array}$ & $\begin{array}{l}\text { At health centre } \\
\text { or sub-area } \\
\text { capital town }\end{array}$ & $\begin{array}{l}\text { Guidelines for Work- } \\
\text { shop on LEC for health } \\
\text { workers, pictorial guide } \\
\text { \& posters }\end{array}$ & $\begin{array}{l}1 \text { day or more } \\
\text { depending on } \\
\text { prior level of } \\
\text { training of HW }\end{array}$ \\
\hline $\begin{array}{l}\text { 8. Selecting HW1 and HW2 } \\
\text { and volunteers }\end{array}$ & $\begin{array}{l}\text { PM, TL, local } \\
\text { health officer and } \\
\text { community }\end{array}$ & $\begin{array}{l}\text { At health centre } \\
\text { or sub-area } \\
\text { capital town }\end{array}$ & $\begin{array}{l}\text { Discussion with local } \\
\text { health of ficials }\end{array}$ & - \\
\hline $\begin{array}{l}\text { 9. Conduct of Orientation } \\
\text { Workshop for volunteers }\end{array}$ & $\mathrm{TL}$ & $\begin{array}{l}\text { At health centre } \\
\text { or appropriate } \\
\text { place }\end{array}$ & $\begin{array}{l}\text { Guidelines for Orien- } \\
\text { tation Workshop for } \\
\text { volunteers \& pamphlets }\end{array}$ & Half a day \\
\hline $\begin{array}{l}\text { 10. Visiting villages for } \\
\text { information meetings }\end{array}$ & $\mathrm{TL}$ & $\begin{array}{l}\text { Villages in the } \\
\text { sub-area }\end{array}$ & Local transport & 4-6 weeks \\
\hline $\begin{array}{l}\text { 11. Diagnosis, treatment \& } \\
\text { registration of new cases }\end{array}$ & TL & Village level & $\begin{array}{l}\text { Examination of } \\
\text { suspects }\end{array}$ & $\begin{array}{l}\text { At the time of } \\
\text { village visits }\end{array}$ \\
\hline $\begin{array}{l}\text { 12. Preparation of LEC } \\
\text { reports for each village and } \\
\text { submission of reports }\end{array}$ & TL & Village level & LEC forms & Continuous \\
\hline $\begin{array}{l}\text { 13. Move to next area and } \\
\text { start activity numbers } 6,7,8 \text {, } \\
9,10,11 \& 12\end{array}$ & $\mathrm{TL}$ & $\begin{array}{l}\text { At health centre } \\
\text { or sub-area } \\
\text { capital town }\end{array}$ & Local transport & 1-2 days \\
\hline
\end{tabular}

* LEC guidelines, Guide to Eliminating Leprosy, Workshop Guidelines for health workers \& volunteers, Posters $\mathrm{NPM}=$ National Programme Manager, $\mathrm{PM}=$ Project Manager, TL = Team Leader, HW $=$ Health Worker 


\section{Activity flow diagram for Team Leaders of campaign teams}

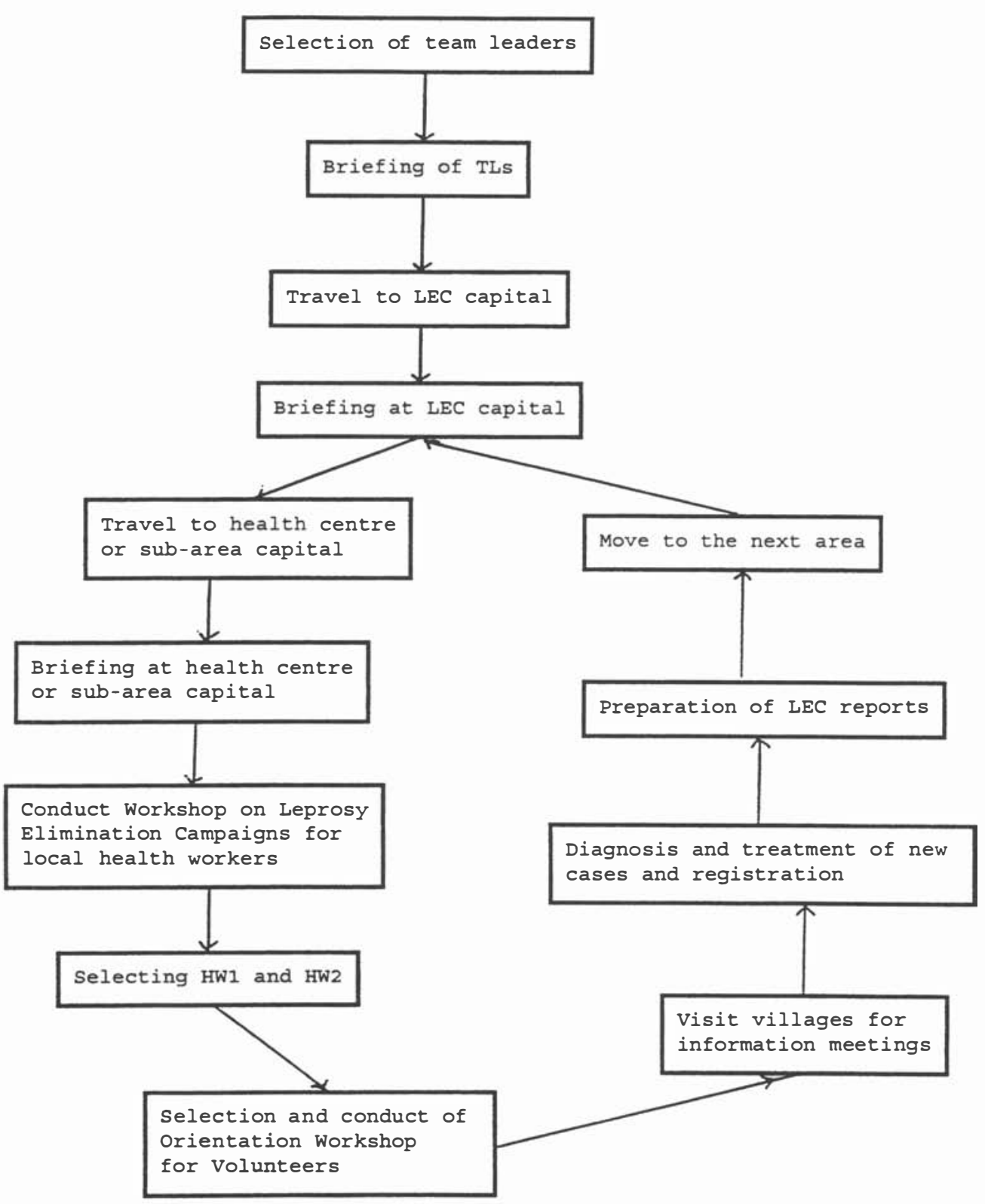


Annex 5.

\section{Reporting forms for teams of leprosy elimination campaign}

1. Name of village/community

2. District/Province

3. Date of visit

4. Village/community population

5. Cases registered for treatment before LEC in $\mathrm{PB}$ the village/community.

$\mathrm{MB}$

6. New case information

\begin{tabular}{lllll} 
Type & $\begin{array}{l}\text { Number of } \\
\text { new cases }\end{array}$ & $\begin{array}{l}\text { New cases with } \\
\text { patches }\end{array}$ & $\begin{array}{l}\text { Number of } \\
\text { new cases } \\
\text { under 15 } \\
\text { years }\end{array}$ & $\begin{array}{l}\text { Number of } \\
\text { new cases with } \\
\text { grade } 2 \\
\text { disability }\end{array}$ \\
\hline PB & & & \\
MB & & & \\
Total & & & \\
\hline
\end{tabular}

Signature

Name

Date 
Annex 6.

\section{Outline for proposal of leprosy elimination campaigns}

1. Name, designation and institution of the individual submitting the proposal.

2. Description of the area selected for LEC.

- Geography, population, number of villages/communities to be covered and communications.

- Map showing villages and health centres.

- General information about leprosy elimination activities in this area, including categories of workers involved in providing MDT services.

- Specific information on leprosy (registered prevalence, estimated prevalence, number of new cases detected, new case grade 2 disability during the previous years, and present MDT coverage and health service coverage).

3. Organization of LEC team.

- Name, designation and institution of project manager.

- How the TLs are to be recruited.

- How the other members of the campaign teams will be identified and mobilized for campaign activities.

4. Activities planned under LEC.

5. Time frame of major activities and timing of campaign.

6. Detailed costing of proposed LEC activities.

7. Supervision and Monitoring of LEC.

- How is it to be done and by whom?

8. Address to which funds are to be sent. 
Annex 7.

\section{Outline for final report of leprosy elimination campaign}

1. General information about the area.

- Geography, population and number of villages/community covered.

- Map of campaign area.

2. Leprosy situation of the area (before LEC).

- Information on how leprosy elimination activities are carried out in this area and on the MDT situation.

- Registered prevalence.

- Estimated prevalence.

- New case detection (PB and MB) during the past three years.

- New case grade 2 disability.

- MDT coverage.

- Health services coverage.

3. General information about LEC.

- What activities have been carried out?

- When were they done?

- What posters, pamphlets or mass media education messages were used during the campaigns?

- How many teams were deployed and manpower used?

- Community acceptance of LEC?

4. Specific information about LEC.

- Number of new cases detected during the campaign (PB and MB).

- Number of new cases detected during the campaign with more than five skin patches.

- Number of new cases with grade 2 disability detected during the campaign.

- Number of local health workers trained in the workshops.

- Number of local health workers actually involved in LEC activities.

- Number of volunteers involved in LEC.

- Number of villages/communities visited by the campaign teams.

- MDT coverage.

5. Financial statement on LEC.

- Travel and per diem allowances.

- Production of posters, pamphlets and training materials.

- Supply and equipment.

- Others (please specify).

6. Overall comments (National Programme Manager and Project Manager). 